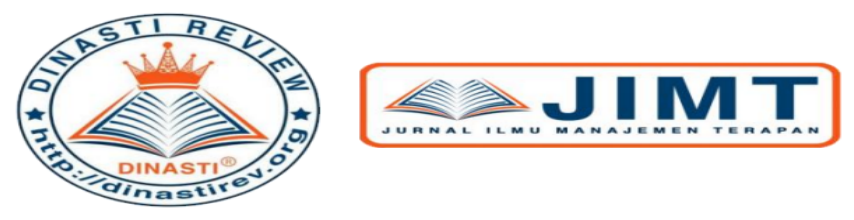

+62 878-9658-6407

087896586407

https://dinastirev.org/JIMT editor@dinastirev.org

\title{
ANALISIS STRATEGI PENINGKATAN KINERJA BAGIAN SEKRETARIAT PADA DINAS PENDIDIKAN, PEMUDA DAN OLAHRAGA KOTA PADANG
}

\section{Arbiuddin Syahputra Hakim Harahap \\ Universitas Putra Indonesia "YPTK" Padang}

\begin{tabular}{|c|c|}
\hline $\begin{array}{l}\text { ARTICLE INFORMATION } \\
\text { Received: } 11 / 09 / 2019 \\
\text { Revised: } 21 / 09 / 2019 \\
\text { Issued: } 28 \text { September } 2019 \\
\text { (filled in by Editor) }\end{array}$ & $\begin{array}{l}\text { Abstrak: Penelitian ini bertujuan untuk mengetahui } \\
\text { bagaimana Strategi Peningkatan Kinerja Bagian } \\
\text { Sekretariat Pada Dinas Dikpora Kota Padang. Metode } \\
\text { penelitian yang digunakan dalam penelitian ini adalah } \\
\text { tipe penelitian deskriptif, dengan populasinya seluruh pe } \\
\text { gawai Bagian Sekretariat pada Dinas Dikpora Kota } \\
\text { Padang. Sampel ditarik secara non probability sampling } \\
\text { dengan penetapan anggota sampel ditentukan dengan } \\
\text { teknik sampling jenuh, maka sampel diambil dari semua } \\
\text { anggota populasi yang ada dengan memperhatikan segi } \\
\text { objektivitas. Selanjutnya, teknis analisis yang digunakan } \\
\text { untuk membuktikan pengujian hasil penelitian adalah } \\
\text { dengan teknik analisis SWOT. Berdasarkan hasil analisis } \\
\text { SWOT menunjukkan bahwa untuk meningkatkan kinerja } \\
\text { Bagian Sekretariat pada Dinas Dikpora Kota Padang } \\
\text { perlu memperhatikan kekuatan organisasi yang sangat } \\
\text { dominan terdiri dari; Manajemen dan Struktur } \\
\text { Organisasi serta Prosedur dan Kewenangan } \\
\text { Organisasi dengan TNB sebesar 3,81; kelemahan } \\
\text { organisasi yang teridentifikasi yaitu kualitas SDM } \\
\text { masih rendah serta sarana dan prasarana penunjang } \\
\text { relatif masih kurang. } \\
\text { Kata Kunci: Analisis Strategi, Analisis SWOT, Kinerja, } \\
\text { Pendidikan, Pemuda dan Olahraga. }\end{array}$ \\
\hline
\end{tabular}

\section{PENDAHULUAN}

Kinerja birokrasi pemerintahan dewasa ini menuntut adanya pemahaman penting terhadap peningkatan kemampuan aparatur pemerintah agar menjadi pegawai yang mandiri dan profesional. Salah satu hal yang sangat mendesak untuk diwujudkan adalah bagaimana menciptakan kinerja pegawai yang lebih baik dalam hal pelayanan publik. Beberapa kajian ilmiah berkaitan dengan masalah kinerja pegawai yang dilakukan oleh Badan Penelitian dan Pengembangan Kepegawaian (2002:8) memberikan indeks hasil penilaian terhadap kinerja pegawai ditentukan oleh unsur-unsur variabel yang berpengaruh terhadap upaya pengembangan sumber daya manusia. Penelitian ini merekomendasikan bahwa pengembangan kemampuan sumber daya aparatur pemerintahan perlu dilakukan secara simultan dan berkesinambungan dalam upaya mengoptimalkan kinerja pegawai. Untuk mencapai hal tersebut tentunya diperlukan perencanaan strategi yang tepat dan akurat sesuai 
dengan tujuan yang ingin dicapai. Sesuai Pasal 3 Undang-undang Nomor 28 Tahun

1999 tentang Penyelenggaraan Negara yang Bersih dan Bebas dari Korupsi, Kolusi, dan Nepotisme, disebutkan bahwa asas-asas umum penyelenggaraan negara meliputi: asas kepastian hukum, asas tertib penyelenggara negara, asas kepentingan umum, asas keterbukaan, asas proporsionalitas, asas profesionalitas, dan asas akuntabilitas. Selanjutnya, dijelaskan pada penjelasan Undang-undang tersebut, asas akuntabilitas kinerja adalah asas yang menentukan bahwa setiap dan hasil akhir dari kegiatan penyelenggaraan negara harus dapat dipertanggungjawabkan kepada masyarakat atau rakyat sebagai pemegang kedaulatan tertinggi negara dengan ketentuan peraturan perundangundangan yang berlaku.

Pelaksanaan pertanggungjawaban kinerja instansi pemerintah tersebut dilakukan melalui sistem akuntabilitas dan media pertanggungjawaban secara periodik dan melembaga. Apabila mencermati permasalahan yang muncul dewasa ini menunjukkan bahwa kinerja instansi pemerintah banyak menjadi sorotan publik, terutama sejak timbulnya iklim yang lebih demokratis dalam pemerintahan. Masyarakat mulai mempertanyakan akan nilai yang mereka peroleh atas pelayanan yang dilakukan oleh instansi pemerintah. Nampaknya, masyarakat belum merasa puas terhadap kualitas jasa pelayanan yang diberikan oleh instansi pemerintah. Oleh sebab itu, kinerja pegawai dipandang perlu untuk ditingkatkan melalui upaya analisis yang lebih mendalam mengenai apa sebenarnya elemen-elemen kunci keberhasilan yang harus dilakukan melalui teknik analisis SWOT yang meliputi; kekuatan, kelemahan, peluang dan ancaman terhadap organisasi dimana pegawai itu bekerja.

\section{KAJIAN PUSTAKA}

\section{Konsep Kinerja}

Kinerja secara sederhana adalah prestasi kerja atau hasil pelaksanaan kerja. Istilah kinerja berasal dari kata "performance". Sedangkan pengukuran kinerja disebut dengan "performance measurement", Bernardin dan Russel dalam Gomes (1994:146) mendefinisikan kinerja adalah catatan hasil outcomes yang dihasilkan dari fungsi suatu pekerjaan atau kegiatan tertentu selama suatu periode waktu tertentu. Sedangkan pengukuran kinerja adalah sebagai suatu metode untuk menilai kemajuan/hasil yang telah dicapai dibandingkan dengan tujuan yang telah ditetapkan (LAN-RI, 2000:5).

Simamora (1997:415) menjelaskan bahwa pada intinya penilaian kinerja (prestasi kerja) dapat dianggap sebagai alat untuk memverifikasi bahwa individu memenuhi standar kinerja yang telah ditetapkan. Penilaian kinerja dapat pula menjadi cara untuk membantu individu untuk mengelola kinerjanya, dan kinerja dapat dilihat dari berbagai sudut pandang tergantung kepada tujuan masing-masing organisasi. Kinerja sering dihubungkan dengan tingkat produktivitas yang menunjukkan ratio input dan output dalam organisasi, bahkan dapat dilihat dari sudut performance dengan memberikan penekanan pada nilai efisiensi yang dikaitkan dengan kualitas output yang dihasilkan oleh pegawai berdasarkan beberapa standar yang telah ditetapkan sebelumnya oleh organisasi yang bersangkutan.

\section{Analisis Manajemen}

Menurut Sianipar \& Entang (2001:19-20) analisis manajemen adalah mencari dan menentukan atau memilih faktor kunci sukses yang akan diberdayakan dan kelemahan yang akan diperbaiki, serta ancaman yang akan diatasi agar organisasi tetap memiliki keunggulan 
untuk meraih peluang strategis yang memberikan manfaat yang lebih besar dan memuaskan semua stakeholders atau mencapai tujuan dan sasaran yang telah ditetapkan.

Dalam pelaksanaan analisis manajemen ada serangkaian kegiatan yang memerlukan berbagai teknik: (1) Teknik penentuan tujuan dengan analisis kesenjangan kinerja organisasi, atau dengan pendekatan top down atau bottom up. (2) Teknik identifikasi dengan brainstorming dan atau check sheet. (3) Teknik penilaian dengan menggunakan skala nilai tertentu. (4) Teknik pemilihan faktor-faktor unggulan dengan menggunakan beberapa alat seperti; diagram Pareto, metode komparasi, matriks prioritas masalah, USG. (5) Teknik mencari akar penyebab dengan diagram fishbone, diagram pohon masalah, dan causal map.(6) Teknik penyusunan strategi dengan formulasi Matriks SWOT Analysis. (7) Teknik penyusunan rencana kegiatan dengan $5 \mathrm{~W}$ dari $1 \mathrm{H}$. (8) Teknik evaluasi dengan membandingkan realisasi dan rencana atau target.

\section{METODE PENELITIAN}

Populasi dalam adalah keseluruhan pegawai (PNS) Bagian Sekretariat pada Dinas Dikpora Kota Padang yang berjumlah 17 orang. Mengingat jumlah populasi yang relatif kecil, maka peneliti menggunakan teknik sampel jenuh, dimana keseluruhan populasi yang ada dijadikan sebagai sampel penelitian. Hal ini sejalan dengan pendapat yang dikemukakan oleh Sugiyono (2005:91) yang menyatakan bahwa sampel jenuh adalah teknik penentuan sampel bila semua anggota populasi digunakan sebagai sampel. Dengan demikian maka jumlah sampel dalam penelitian ini ditetapkan berjumlah 17 orang. Data hasil penelitian dianalisis dengan menggunakan metode Analisis SWOT yaitu sebagai alat analisis yang dipandang cukup ampuh untuk melakukan analisis, keampuhan tersebut terletak pada kemampuan para penentu strategi organisasi yang berperan dalam organisasi. Analisis SWOT adalah alat untuk memaksimalkan kekuatan (strengths) dan pemanfaatan peluang (opportunities) sekaligus berperan sebagai alat untuk meminimalisasi kelemahan (weaknesses) dalam tubuh organisasi dan menekan dampak ancaman (treats) yang timbul dan harus dihadapi (Siagian, 2004:172).

\section{HASIL DAN PEMBAHASAN}

Berdasarkan hasil analisis lingkungan internal dan eksternal organisasi Bagian Sekretariat pada Dinas Dikpora Kabupaten Banggai, maka dalam pembahasan hasil penelitian ini, penulis melakukan pemberian nilai dan bobot sesuai dengan tanggapan responden berdasarkan peringkat dan masing-masing indikator yang termasuk dalam analisis identifikasi lingkungan internal dan eksternal organisasi. Setiap indikator akan diurutkan sesuai dengan aspek urgensinya (kepentingan/prioritas) yang ada dalam organisasi. Adapun matriks urgensi faktor internal dan eksternal, seperti pada tabel berikut:

Tabel 1. Evaluasi Faktor-faktor Internal dan Eksternal

\begin{tabular}{|c|c|c|c|c|c|c|c|}
\hline No. & F alchom- Intermal dan Flestermal & 10096 & NND & NED & NWERE & NER & TNB \\
\hline $\begin{array}{l}1 . \\
\frac{2}{3} \\
4\end{array}$ & 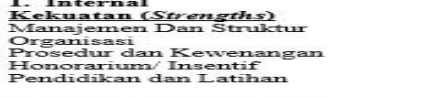 & $\begin{array}{l}17-6 \\
23=5 \\
11=5 \\
5=9\end{array}$ & $\begin{array}{l}3 \\
\frac{3}{2} \\
\frac{2}{1}\end{array}$ & $\begin{array}{l}0,53 \\
0=94 \\
g=24 \\
0=10\end{array}$ & $\frac{4}{\frac{4}{2}}$ & $\begin{array}{l}0.70 \\
0,94 \\
0: 24 \\
0=12\end{array}$ & $\begin{array}{l}1.23 \\
1,39 \\
0,48 \\
0,28 \\
3,81\end{array}$ \\
\hline $\begin{array}{l}1: \\
3 \\
4 \\
4\end{array}$ & 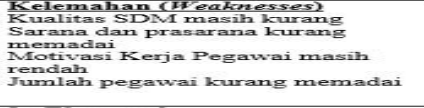 & 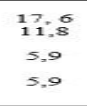 & $\begin{array}{l}\frac{3}{2} \\
1 \\
1\end{array}$ & $\begin{array}{l}0,53 \\
0,24 \\
0,10 \\
0,10\end{array}$ & $\begin{array}{l}\frac{4}{3} \\
3 \\
2\end{array}$ & $\begin{array}{l}0,70 \\
0,35 \\
0,12 \\
0,12\end{array}$ & $\begin{array}{l}1,23 \\
0,39 \\
0,22 \\
0,22 \\
2,20\end{array}$ \\
\hline $\begin{array}{l}\frac{1}{2} \\
3 .\end{array}$ & 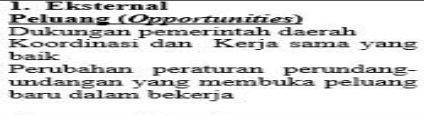 & $\begin{array}{l}23: 3 \\
11,6 \\
11,8\end{array}$ & $\begin{array}{l}\frac{4}{3} \\
=\end{array}$ & $\begin{array}{l}8,94 \\
0,33 \\
0=24\end{array}$ & $\begin{array}{l}\frac{4}{4} \\
3\end{array}$ & $\begin{array}{l}0,94 \\
0,50 \\
0,35\end{array}$ & $\begin{array}{l}1=885 \\
=23 \\
0=50\end{array}$ \\
\hline $\begin{array}{l}\frac{1}{2} \\
3 .\end{array}$ & 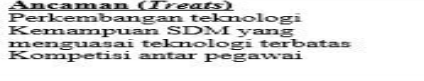 & $\begin{array}{c}17=6 \\
11=8 \\
5.9\end{array}$ & $\begin{array}{l}3 \\
4 \\
1\end{array}$ & $\begin{array}{l}0=57 \\
0.47 \\
0.10\end{array}$ & $\begin{array}{l}4 \\
4 \\
2\end{array}$ & $\begin{array}{l}0,70 \\
0,47 \\
0.12\end{array}$ & $\begin{array}{l}1,23 \\
0,94 \\
0.22 \\
2,392\end{array}$ \\
\hline
\end{tabular}


Berdasarkan tabel 4 tersebut di atas, selanjutnya dapat ditentukan faktor-faktor kunci keberhasilan untuk masing-masing faktor baik faktor internal maupun faktor eksternal dengan melihat nilai TNB terbesar. Untuk masing-masing faktor kunci keberhasilan tersebut dapat dilihat pada rangkuman berikut :

\section{Faktor Internal}

a. Kekuatan (strengths) organisasi pada Bagian Sekretariat Dinas Dikpora Kota Padang adalah Manajemen dan Struktur Organisasi serta Prosedur dan Kewenangan yang dimiliki dengan TNB yaitu 3,81.

b. Kelemahan (weakness) organisasi pada Bagian Sekretariat Dinas Dikpora Kota Padang dalah Kualitas SDM masih kurang dan Sarana dan prasarana kurang memadai dengan TNB yaitu 2,26

\section{Faktor Eksternal}

a. Peluang (opportunities) organisasi Bagian Sekretariat pada Dinas Dikpora Kota Padang adalah Dukungan pemerintah daerah dengan TNB yaitu 3,70.

b. Ancaman (threats) organisasi Bagian Sekretariat pada Dinas Dikpora Kota Padang adalah Perkembangan teknologi dan Kemampuan SDM yang menguasai teknologi terbatas dengan TNB yaitu 2,39.

Setelah diperoleh faktor-faktor kunci keberhasilan untuk masing-masing faktor baik faktor internal maupun faktor eksternal, selanjutnya digambarkan analisis peta kekuatan dan formulasi Strategi Analisis SWOT sebagai berikut:

$$
\mathrm{O}=3,70
$$

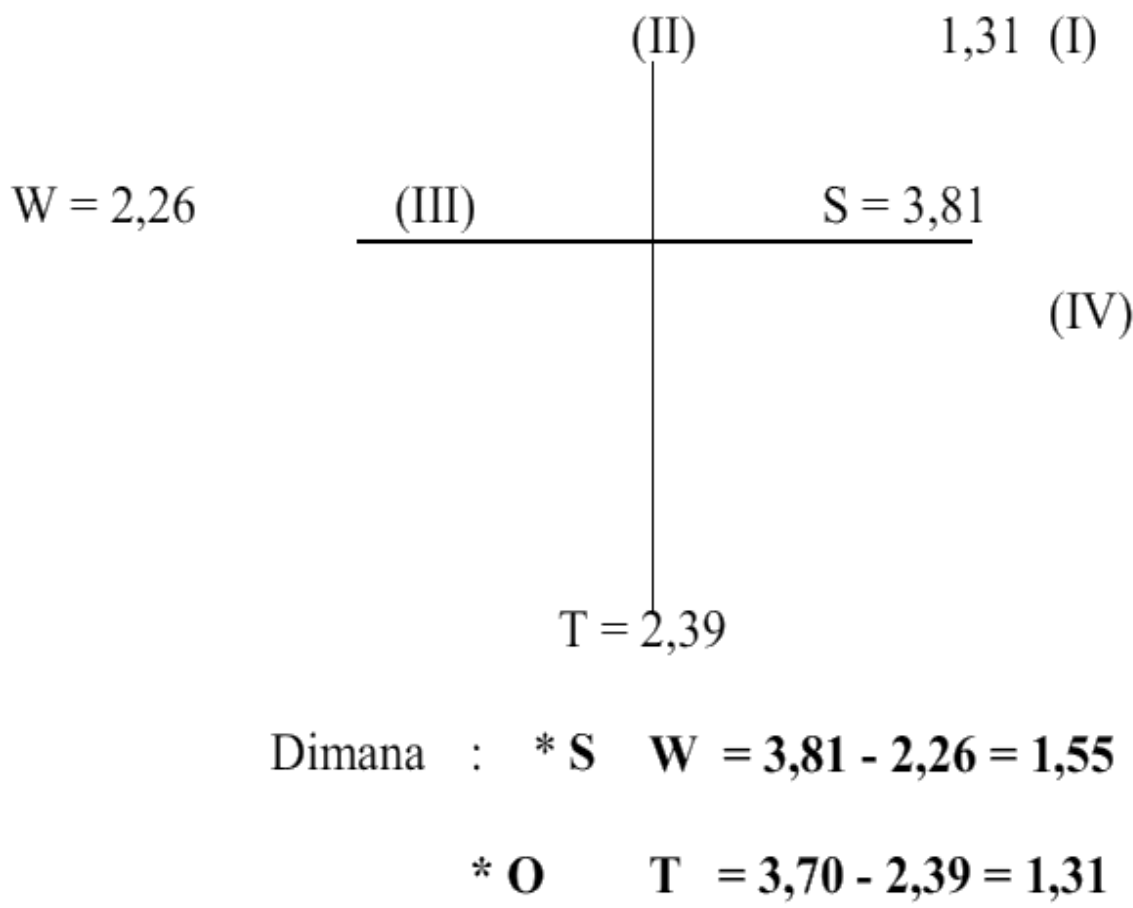

Dengan memperhatikan peta kekuatan organisasi tersebut di atas, maka dapat disimpulkan bahwa kinerja organisasi berada pada kuadran I. Hal ini menunjukkan bahwa situasi yang sangat menguntungkan karena memiliki peluang dan kekuatan sehingga dapat memanfaatkan segala peluang dan kekuatan yang ada (Rangkuti, F,2002). Olehnya sebab itu, Kinerja Bagian Sekretariat pada Dinas Dikpora Kabupaten Banggai mempunyai peluang untuk ditingkatkan dengan memperhatikan seluruh kekuatan/potensi organisasi yang dimiliki. 
Tabel 2. Matriks formulasi SWOT Analysis

\begin{tabular}{|c|c|c|}
\hline & STRENGHTS (S) & WEAKNESSES (W) \\
\hline & $\begin{array}{l}\text { 1. Manajemen Dan Struktur } \\
\text { Organisasi }(1,23) \\
\text { 2. Prosedur dan Kewenangan } \\
(1,88) \\
\text { 3. Honorarium/ Insentif } \\
(0,48) \\
\text { 4. Pendidikan dan } \\
(0,22)\end{array}$ & $\begin{array}{l}\text { 1. Kualitas SDM masih } \\
\text { kurang }(1,23) \\
\text { 2. Sarana dan prasarana kurang } \\
\text { memadai }(0,59) \\
\text { 3. Motivasi Kerja Pegawai } \\
\text { masih } \\
\text { rendah }(0,22) \\
4 \text { Jumlah pegawai kurang }\end{array}$ \\
\hline 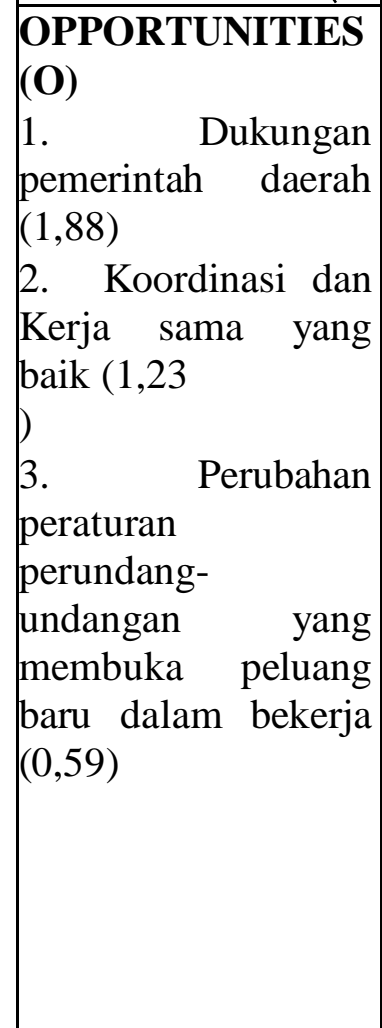 & $\begin{array}{l}\text { STRATEGI SO: } \\
1 \text { Manfaatkan Manajemen dan } \\
\text { Struktur Org yang sehat untuk } \\
\text { mendukung program-program } \\
\text { kegiatan yang sudah ditetapkan. } \\
\text { 2Lakukan koordinasi yang } \\
\text { baik dengan pemerintah } \\
\text { daerah dalam } \text { upaya } \\
\text { mendukung } \\
\text { program program- } \\
\text { berorientasi pada pelayanan } \\
\text { publik. } \\
\text { 3Tingkatkan } \\
\text { organisasi melalui pemberian } \\
\text { Honorarium/ insentif yang } \\
\text { sesuai dengan hasil kerja } \\
\text { pegawai. } \\
\text { 4Gunakan prosedur dan } \\
\text { kewenangan yang ada untuk } \\
\text { meningkatkan } \\
\text { pelayanan publik. }\end{array}$ & $\begin{array}{l}\text { STRATEGI WO: } \\
\text { 1. Manfaatkan dukungan } \\
\text { pemerintah daerah untuk lebih } \\
\text { menumbuhkembangkan potensi } \\
\text { yang dimiliki organisasi dan } \\
\text { pengadaan sarana dan prasarana } \\
\text { yang menunjang pelaksanaan } \\
\text { tugas. } \\
\text { 2. Lakukan perencanaan dan } \\
\text { pemantapan kualitas SDM dan } \\
\text { peningkatan sarana dan prasarana } \\
\text { organisasi. } \\
\text { 3. Lakukan koordinasi dan } \\
\text { kerja sama yang baik dalam } \\
\text { upaya meningkatkan motivasi } \\
\text { kerja, disiplin, dan kinerja } \\
\text { pegawai. Intensifkan koordinasi } \\
\text { 4. } \\
\text { dengan Bupati dan semua SKPD } \\
\text { dalam rangka rekruitmen } \\
\text { pegawai yang handal. }\end{array}$ \\
\hline TREATS (T) & STRATEGI ST: & STRATEGI WT: \\
\hline $\begin{array}{l}\text { 1. Perkembangan } \\
\text { teknologi }(1,23) \\
\text { 2. } \quad \text { Kemampuan } \\
\text { SDM } \\
\text { yang menguasai } \\
\text { teknologi } \\
\text { terbatas } \\
(0,94) \\
\text { 3. Kompetisi } \\
\text { antar pegawai }(0,24)\end{array}$ & 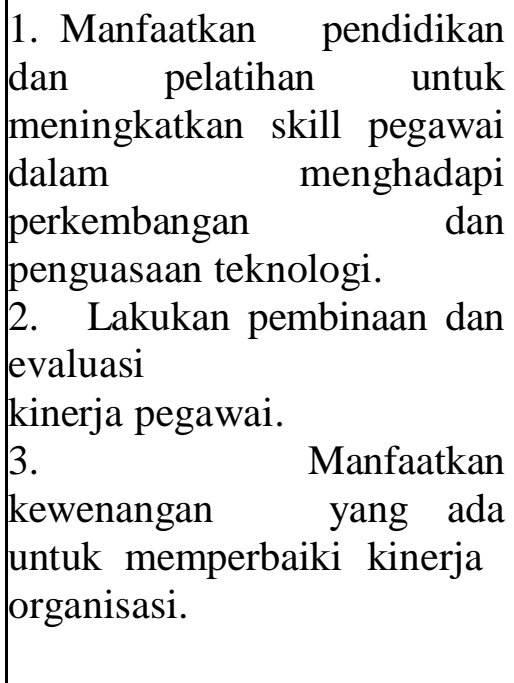 & $\begin{array}{l}\text { 1. Tingkatkan kemampuan } \\
\text { SDM dalam menguasai teknologi } \\
\text { melalui pendidikan dan pelatihan } \\
\text { dan penyediaan sarana dan } \\
\text { prasarana penunjang. } \\
\text { 2. Lakukan upaya untuk } \\
\text { memotivasi dan } \\
\text { mendisiplinkan pegawai agar } \\
\text { kinerja dan produktivitas } \\
\text { meningkat. } \\
\text { 3. Sesuaikan rekruitmen } \\
\text { pegawai dengan } \\
\text { kemampuan } \\
\text { yang dibutuhkan. }\end{array}$ \\
\hline
\end{tabular}




\section{KESIMPULAN}

Berdasarkan hasil analisis data penelitian dan pembahasan strategi peningkatan kinerja pegawai Bagian Sekretariat pada Dinas Dikpora Kota Padang dengan teknik Analisis SWOT dapat disimpulkan bahwa hasil analisis strategi peningkatan kinerja Bagian Sekretariat pada Dinas Dikpora Kota Padang termasuk dalam Kuadran I, artinya Dinas Dikpora Kota Padang memiliki kondisi yang sangat menguntungkan untuk mendukung pencapaian kinerja yang lebih baik.

Adapun beberapa strategi yang digunakan dalam rangka meningkatkan kinerja Bagian Sekretariat pada Dinas Dikpora Kota Padang yaitu; Strategi SO (strength opportunities) yaitu; (1) memanfaatkan Manajemen dan Struktur organisasi yang sehat untuk mendukung program- program kegiatan yang sudah ditetapkan; (2) melakukan koordinasi yang baik dengan pemerintah daerah dalam upaya mendukung program-program kegiatan yang berorientasi pada pelayanan publik; (3)meningkatkan kinerja organisasi melalui pemberian honorarium/insentif yang sesuai dengan hasil kerja pegawai; dan (4) menggunakan prosedur dan kewenangan yang ada untuk meningkatkan kinerja pelayanan publik. Strategi WO (weaknesses opportunities) yaitu;(1) Manfaatkan dukungan pemerintah daerah untuk lebih menumbuhkembangkan potensi yang dimiliki organisasi dan pengadaan sarana dan prasarana yang menunjang pelaksanaan tugas; (2) Lakukan perencanaan dan pemantapan kualitas SDM dan peningkatan sarana dan prasarana organisasi; (3) Lakukan koordinasi dan kerja sama yang baik dalam upaya meningkatkan motivasi kerja, disiplin, dan kinerja pegawai; dan (4) Intensifkan koordinasi dengan Bupati dan semua SKPD dalam rangka rekruitmen pegawai yang handal. Sedangkan strategi ST (strength treats) terdiri dari:(1) Manfaatkan pendidikan dan pelatihan untuk meningkatkan skill pegawai dalam menghadapi perkembangan dan penguasaan teknologi; (2) Lakukan pembinaan dan evaluasi kinerja pegawai; dan (3) Manfaatkan kewenangan yang ada untuk memperbaiki kinerja organisasi. Dan Strategi WT (weaknesses treats) yaitu; (1) Tingkatkan kemampuan SDM dalam menguasai teknologi melalui pendidikan dan pelatihan serta penyediaan sarana dan prasarana penunjang; (2) Lakukan upaya untuk memotivasi dan mendisiplinkan pegawai agar kinerja dan produktivitas meningkat; dan (3) Sesuaikan rekruitmen pegawai dengan kemampuan dan skill yang dibutuhkan.

\section{DAFTAR RUJUKAN}

Gomes, Foustino Cardoso (2001). Manajemen Sumber Daya Manusia, PT. Andi Offset, Yokyakarta.

Instruksi Presiden Nomor 7 Tahun 1999 tentang Akuntabilitas Kinerja Instansi Pemerintah (AKIP) Jakarta.

LAN-RI., (2000). Sistem Administrasi Negara Republik Indonesia, Lembaga Administrasi Negara Republik Indonesia (LAN-RI), Jakarta

Mustopadidjaja, A.R., (2003). Pengukuran Kinerja Instansi Pemerintah, Modul 3 dari 5 Modul Sosialisasi Sistem Akuntabilitas Kinerja Instansi Pemerintah (AKIP), LANRI dan Badan Pengawas Keuangan Dan Pembangunan, Jakarta.

Rangkuti, F., 2005. Analisis SWOT Teknik Membedah Kasus Bisnis, Cetakan ke-12, PT.Gramedia Pustaka, Jakarta.

Salusu, J., (2003). Pengambilan Keputusan Stratejik, Untuk Organisasi Publik dan Organisasi Nonprofit, Grasindo, Jakarta.

Siagian, S.P., (2004). Manajemen Stratejik, Bumi Aksara, Jakarta.

Sianipar dan Entang (2001). Teknik-teknik Analisis Manajemen (TAM) Modul Diklat 
Kepemimpinan Tingkat III, Lembaga Administrasi Negara (LAN) RI, Jakarta.

Sugiyono, (2005). Metode Penelitian Administrasi, Alfabeta, Bandung. 